
\title{
A sobrecarga da família que convive com a realidade do
transtorno mental*
}

\author{
Stress on families living with the reality of mental disorder \\ La sobrecarga de la familia que convive con la realidad del trastorno mental
}

Letícia de Oliveira Borba ${ }^{1}$, Eda Schwartz $^{2}$, Luciane Prado Kantorski ${ }^{3}$

\begin{abstract}
RESUMO
Objetivo: Conhecer a sobrecarga da família que convive com o sofrimento psíquico. Métodos: Trata-se de uma pesquisa qualitativa, com abordagem hermenêutico-dialética. Os dados foram coletados por meio de entrevista semi-estruturada, com dez familiares de portadores de transtorno mental em um Centro de Atenção Psicossocial e no domicílio dos sujeitos. Os dados coletados foram agrupados em temáticas para posterior análise. Resultados: Identificamos a presença de três tipos de sobrecarga: a sobrecarga financeira, relacionada aos gastos com consultas e medicamentos; a sobrecarga do cuidado, pois este fica sob responsabilidade de uma única pessoa; a sobrecarga física, e a emocional representada pela tensão e nervosismo. Conclusão: Evidencia-se, a necessidade de atenção à família dos portadores de transtorno mental, uma vez que favorecidas as estratégias de enfrentamento, ela possa se constituir em um espaço terapêutico e ressocializador.
\end{abstract}

Descritores: Relações familiares; Família; Transtornos mentais; Saúde mental

\begin{abstract}
Objective: To be acquainted with the stress over families living with psychic disorder. Methods: This is a qualitative research, with a hermeneutic-dialectic approach. Data was collected through semi-structured interviews with ten family members of mentally ill persons in a Psychosocial Attention center and on their homes. Gathered data was grouped in themes for later analysis. Results: We identified the presence of three overload types: financial overload, related to medicine and consultation spending; attention overload, because it's the responsibility of a single individual; physical and emotional overload, represented by tension and anxiety. Conclusion: The need for attention of the family of the mentally ill is evidenced. Once the the coping strategies are grasped, it can become a therapeutical and resocializing space.

Keywords: Family relations;Family; Mental disorders; Mental health
\end{abstract}

\section{RESUMEN}

Objetivo: Conocer la sobrecarga de la familia que convive con el sufrimiento psíquico. Métodos: Se trata de una investigación cualitativa, con abordaje hermenéutico dialéctico. Los datos fueron recolectados por medio de entrevista semi-estructurada, realizada a diez familiares de portadores de trastorno mental en un Centro de Atención Psicosocial y en el domicilio de los sujetos. Los datos recolectados fueron agrupados en temáticas para un posterior análisis. Resultados: Identificamos la presencia de tres tipos de sobrecarga: la sobrecarga financiera, relacionada a los gastos con consultas y medicamentos; la sobrecarga del cuidado, pues éste queda bajo la responsabilidad de una sola persona; la sobrecarga física, y la emocional representada por la tensión y el nerviosismo. Conclusión: Se evidencia, la necesidad de atención a la familia de los portadores de trastorno mental, de tal modo que favorecidas las estrategias de enfrentamiento, ella se pueda constituir en un espacio terapéutico y resocializador.

Descriptores: Relaciones familiares; Familia; Trastornos mentales; Salud mental

\footnotetext{
* Parte da pesquisa de Avaliação dos Centros de Atenção Psicossocial da Região Sul do Brasil (CAPSUL). Estudo multicêntrico coordenado pela Profa. Dra. Luciane Prado Kantorski da Faculdade de Enfermagem e Obstetrícia da Universidade Federal de Pelotas, desenvolvido em pareceria com a Escola de Enfermagem da UFRGS e o Curso de Enfermagem da UNIOESTE - Cascavel (PR), Brasil. Pesquisa financiada pelo CNPq em parceria com o Ministério da Saúde através do Edital 07/2005.

${ }^{1}$ Pós-graduanda do Programa de Pós-Graduação em Enfermagem da Universidade Federal do Paraná - UFPR - Curitiba (PR), Brasil. Bolsista CAPES.

${ }^{2}$ Doutora. Professora Adjunto da Faculdade de Enfermagem e Obstetrícia da Universidade Federal de Pelotas -UFPel-Pelotas (RS), Brasil.

${ }^{3}$ Doutora. Professora Adjunto da Faculdade de Enfermagem e Obstetrícia da Universidade Federal de Pelotas - UFPel -Pelotas (RS), Brasil.
} 


\section{INTRODUÇÃO}

As novas perspectivas referentes à atenção em saúde, como a criação do Programa Saúde da Família, a redução do tempo de internação, os cuidados prestados no domicílio, os incentivos para tratamentos em unidades ambulatoriais, uma rede social mais ampla e a flexibilidade na assistência a portadores de doenças de longa duração, estimulam a inclusão da família no processo de cuidar ${ }^{(1)}$.

A responsabilidade pelo cuidado do portador de transtorno mental no contexto que antecede o movimento reformista era atribuída à instituição hospitalocêntrica, restando à família a tarefa de identificar a desorganização, encaminhar o familiar, visitá-lo, bem como fornecer as informações necessárias sobre a história de sua enfermidade. A relação do institucionalizado com a própria família, era mediada por agentes médicos e estatais, encarregados da cura, custódia e assistência ${ }^{(2)}$.

A partir da década de 60 do século XX em países como a Itália, e dos anos 80 no Brasil, a necessidade de se repensar as práticas em saúde mental torna-se evidente, em face das condições desumanas de tratamento a que eram expostos os portadores de transtorno psíquico, mantidos distantes da sociedade e dos seus familiares ${ }^{(2)}$.

A reforma psiquiátrica defende o processo de desinstitucionalização com conseqüente substituição dos manicômios por novos dispositivos de acolhimento e tratamento, surgindo assim: os Núcleos de Atenção Psicossocial (NAPS), os Centros de Atenção Psicossocial (CAPS), o Hospital Dia, o Programa de Residência Terapêutica, os leitos psiquiátricos em Hospital Geral. Formas de tratamento que rompem com os paradigmas do modelo asilar ${ }^{(3)}$.

Os serviços de atenção comunitária em saúde mental devem incluir ações dirigidas aos familiares e comprometerem-se com a construção de projetos de inserção social, respeitando as possibilidades individuais e os princípios de cidadania que minimizem o estigma e promovam a qualidade de vida dos portadores de sofrimento psíquico ${ }^{(3)}$.

Tendo em vista a reformulação da assistência psiquiátrica, a unidade familiar assume um importante papel no cuidado e ressocialização dos sujeitos que sofrem de enfermidade mental. Portanto, é necessário conhecer o universo familiar e como seus integrantes reagem e convivem com o sofrimento psíquico ${ }^{(4)}$.

"A família é o primeiro sujeito que referencia e totaliza a proteção e a socialização dos indivíduos", independente das múltiplas formas e contornos que ela assuma, é nela que se inicia o aprendizado dos afetos e das relações sociais ${ }^{(5)}$.

A família é conceituada como um sistema formado por valores, crenças, conhecimentos e práticas que direcionam suas ações na promoção da saúde de seus integrantes, zelando pela prevenção e o tratamento da doença. Intrínseco ao conceito de família como sistema está o processo de cuidar, no qual a família define estratégias a seguir em caso de queixas ou sinal de mal-estar ${ }^{(6)}$.

A presença do sofrimento mental no ambiente familiar provoca mudanças nas rotinas, hábitos e costumes da família. Com o impacto do diagnóstico, a necessidade de adaptação à nova situação, o estigma social, a dependência e as implicações da cronicidade do quadro clínico podem produzir sobrecarga, conflitos, sentimentos de incredulidade, perda do controle e medo, visto que a família vivencia uma situação de desgaste ${ }^{(7)}$.

A convivência com o transtorno mental implica em sobrecarga caracterizada por dificuldades como: problemas no relacionamento com o familiar, estresse por conviverem com o humor instável e a dependência do portador de sofrimento psíquico, bem como o medo das recaídas e do comportamento deste no período das crises ${ }^{(4)}$.

A sobrecarga é considerada ainda na sua dimensão objetiva e/ou subjetiva. A primeira, identificada com maior intensidade, talvez por ser mais concreta, está relacionada com as demandas reais que a convivência com o transtorno mental impõe, enquanto a sobrecarga subjetiva é abstrata, refere-se ao universo dos sentimentos ${ }^{(8)}$.

Frente ao impacto do adoecimento, as possibilidades de trocas afetivas que, de fato, sejam verdadeiras ficam reduzidas, impondo aos familiares a vivência de sentimentos e emoções que são difíceis de elaborar e entender. Isto evidencia a necessidade de intervenção que acolha o sofrimento apresentado, considerando a subjetividade e individualidade das pessoas ${ }^{(7)}$.

Ao envolver a família no tratamento do portador de transtorno mental, e ao dar suporte a esta para enfrentar as dificuldades no relacionamento com a loucura e a sobrecarga, a carga emocional da família e do próprio usuário é amenizada, aumentando o nível de interação e empatia entre eles ${ }^{(9)}$.

\section{OBJETIVO}

Conhecer a sobrecarga da família que convive com o sofrimento psíquico.

\section{MÉTODOS}

O Estudo de Avaliação Qualitativa de CAPS da região Sul do Brasil desenvolveu-se a partir da avaliação construtivista, responsiva e da abordagem hermenêuticodialética. No estudo foi utilizada a Avaliação de Quarta Geração, desenvolvida por Egon Guba e Yvona Lincoln, adaptada em $2005^{(10)}$ que norteia, o processo teóricometodológico desta pesquisa.

Em observância aos aspectos éticos, o projeto de pesquisa foi aprovado pelo Comitê de Ética em Pesquisa de uma instituição pública de ensino superior, sendo 
emitido parecer favorável (ofício 074/05); os familiares expressaram sua concordância em participar do estudo por meio da assinatura do Termo de Consentimento Livre e Esclarecido.

Em uma escolha intencional, foram selecionados cinco CAPS, tendo como parâmetro os dados obtidos na etapa de avaliação epidemiológica quantitativa de 30 CAPS da região Sul do Brasil, referentes à estrutura, processo e adequação às normas definidas pela Portaria no 336/2002. Foram também considerados o tempo de funcionamento, a experiência do serviço e a disponibilidade dos grupos de interesse em aderirem à proposta. A etapa qualitativa do estudo concentrou-se em Centros de Atenção Psicossocial I e II, de cinco municípios da região Sul do país.

O presente artigo dedica-se a analisar os dados obtidos em um CAPS II que fez parte deste estudo, especificamente no que se refere ao grupo de interesse dos familiares em relação a sobrecarga familiar mediante o sofrimento psíquico.

A aplicação prática da Avaliação Qualitativa de Quarta Geração aconteceu por meio de:

- Contato com a equipe do serviço, sendo apresentada e discutida a proposta da pesquisa;

- Identificação dos stakeholders ou grupos de interesse formados por pessoas com características comuns, que têm algum interesse no desempenho, no produto ou no impacto do objeto da avaliação. Foram incluídos na pesquisa três grupos de interesse: equipe, usuários e familiares;

- Desenvolvimento e ampliação das construções conjuntas aplicação do círculo hermenêutico-dialético;

- Apresentação das questões para os grupos de interesse organização das construções do grupo, para que pudessem ter a oportunidade de modificá-las ou afirmar a sua credibilidade.

Os sujeitos que compuseram o grupo de interesse dos familiares foram intencionalmente definidos durante a primeira semana em que se realizou um período de observação prévia no serviço. A segunda a e terceira semana do trabalho de campo foram dedicadas à realização das entrevistas com a aplicação do círculo hermenêuticodialético. A inclusão dos sujeitos no estudo aconteceu por meio dos seguintes critérios: familiares com boa ou má inserção no serviço, ser responsável direto pelo cuidado, conviver diariamente com o portador de transtorno mental, familiares considerados "difíceis" pela equipe.

Desse modo, fizeram parte do estudo dez familiares, dos quais dois não referiram em suas falas vivenciar situações de sobrecarga. A fim de garantir os princípios éticos de sigilo e anonimato, os sujeitos foram identificados pela letra E, de entrevistado, numerados de um a oito, conforme a seqüência das entrevistas.

Após cuidadosa leitura das transcrições orientada por um roteiro de análise, os dados foram classificados em diferentes temáticas relacionadas à sobrecarga, confrontando o achado com o material teórico e comentado com base nas reflexões das autoras.

\section{RESULTADOS}

Analisando as entrevistas, identificou-se através das falas dos sujeitos o quanto é desgastante para a família conviver com o sofrimento psíquico, implicando compreender e lidar com comportamentos não-convencionais como falar sozinho, inversão do ciclo de sono, retraimento social, humor inconstante, descuido com a higiene pessoal, os quais terminam por despertar sentimentos ambíguos, como constatamos na seqüência deste estudo.

Sobrecarga financeira: a questão do ônus financeiro para a família do portador de transtorno mental é evidenciada nas falas dos familiares entrevistados como segue:

"Men outro filho teve que faltar na sexta-feira o serviço para poder ficar cuidando dele [...]" (E1)

"Ta ter que parar de trabalhar para cuidar dela [...] en preciso trabalhar, é claro que a única renda de dentro de casa é minha." (E2)

"Se o meu marido parar de trabalhar, ele ganha $\mathrm{R} \$ 350,00$ da aposentadoria e ele trabalha direto [...] pois se ele parar de trabalhar, o que nós vamos comer?" (E3)

"E com o remédio ela não pode trabalhar [...] ela toma remédio muito forte, então ela dorme demais..." (E4)

"Porque tínhamos que comprar a medicação que ele tomava antes dele comesar o acompanhamento aqui e, no caso, era um gasto assim bem alto." (E5)

A sonolência, efeito colateral de alguns psicofármacos, ou parte da sintomatologia clínica, em conjunto com a alteração do comportamento, compromete a participação do portador de sofrimento mental no mercado de trabalho.

Quando analisamos a presença da sobrecarga financeira no contexto diário das famílias esta ganha proporções maiores, pois além da preocupação em suprir as necessidades da casa e do tratamento, os demais integrantes da família sofrem privações, em decorrência do orçamento rígido e controlado.

Sobrecarga do cuidado: as falas dos familiares entrevistados indicam como a família vai se constituindo em um sistema informal de cuidado, zeloso, preocupado e presente.

No contexto do sofrimento psíquico, cuidar torna-se tarefa por vezes difícil, seja pela falta de apoio e comprometimento dos demais membros da família, seja pelas demandas do familiar doente.

"Daí eu não consegui nem ir no banbeiro (familiar da usuária) por causa dela, ela fica muito agitada, ela sai [...] perigoso se machucar, puxar fio de luz, o que tiver na frente [...] ela fica assim 
desorientada, sai para rua sai quase nua, pouca roupa [...] eu cheguei até amarrar na cama, porque eu não conseguia mais, insuportável, fui obrigado." (E2)

"Põe cinza pelo chão, cigarro na cama pode dar um incêndio, deixar fogão ligado, deixar o grill ligado com carnes e ir dormir. Eu me assusto. [...] de repente uma crise de novo, com a faca na mão assim para mim." (E6)

"Ele tenta se matar [...] a gente sempre tem que estar alerta [...] assim qualquer barulbinho eu já estou acordada, você já dorme preocupada, com medo dele levantar, cair, se machucar ou de ele fazer alguma besteira." (E1)

As famílias que convivem com o sofrimento psíquico demonstram preocupação, impotência e medo frente ao comportamento inadequado e imprevisível, da inconstância de humor e do risco de suicídio do familiar com transtorno mental, por vezes tomando atitudes que causam certa perplexidade, mas justificáveis pelo desespero de não mais saber o que fazer para proteger o familiar de danos físicos; este é o modo encontrado pela família para cuidar nesse determinado momento da sua trajetória.

'Doze noites, não dormia mesmo (a usuária) no outro dia en (familiar) não agüentava mais, e ela não pára, ela queria mudar para toda a parte." (E2)

"Tem eu para cuidar, só eu para cuidar, mas eu sozinha [...] eu preciso cuidar de mim também." (E1)

"Eu para levar eles no dentista, para levar no médico, sabe? Por enquanto é tudo eu." (E3)

Percebe-se, pelas falas dos sujeitos, o quão complexo e difícil é este conviver com o sofrimento psíquico, quando a família não consegue se rearticular. Muito além de prover cuidado, o cuidador deixa de lado seus compromissos, anulando suas vontades e necessidades em prol de sanar a dependência do familiar doente, deixando claro que o processo de desinstitucionalização é válido quando se presta assistência também à família, esta precisa aprender a coexistir em um mesmo espaço com uma pessoa carente de cuidado. No entanto, tem a sua vida para organizar, seus compromissos, suas aspirações e desejos.

"Mas tem dia que ai a gente perde as estribeiras [...] Ai, muito dificil, porque a pessoa fica teimosa, a pessoa tem, quer fazer, ela, às vezes ela fugia de casa, a gente não sabia para onde que ela tinha ido, eu fui ficar preocupada, eu chegava de noite em casa [...] Se ela está acordada ela come direto [...] e ela tem insônia também, ela fica acordada à noite todinha." (E4)

"É, mas infelizmente quando tem uma pessoa só é ruim também como eu falei, como é que eu vou só cuidar deles e eu? Então quando eu preciso fazer alguma coisa vou deixar aonde, com quem? como?"(E1)

Evidencia-se a necessidade que as famílias têm de receber orientação, contar com um suporte social organizado e preparado para atender as suas demandas, e apoio para que consigam articular recursos internos para o enfrentamento das situações referentes ao comportamento inadequado apresentado por seu familiar.

A inserção da família em grupos de familiares, nos quais os fatores complexos relacionados a esta situação são discutidos, é benéfica no sentido de mostrar-lhes que não estão sozinhos na tarefa de cuidar e que as dificuldades enfrentadas também são pertinentes às demais famílias que experenciam conviver com o tratamento psíquico, sofrendo diretamente com os momentos de exacerbação dos sintomas da doença mental.

"Então ela não toma a metade do remédio que eu dou. Bota na boca, quando eu saio, ela coloca tudo no chão." (E6)

"Agora medicação dele eu dou toda na mão porque eu tenho medo [... Tem vez que ele quer tomar tudo de uma vez. Eu escondo, ele nem sabe onde que eu boto, só ponho no potinho de tomar e pronto." (E7)

"Eles ficam bem ruim e não dão conta de comerem sozinhos." (E3)

Sobrecarga física e emocional: a presença da sobrecarga física e emocional é identificada pelo aparecimento de doenças relacionadas ao sistema nervoso como gastrite e problemas gastrintestinais, mostrando como os problemas de ordem emocional repercutem sobre a saúde física dos indivíduos. Emocionalmente, as pessoas que convivem com a realidade do transtorno mental encontram-se esgotadas, pela privação do sono ou pelo fato de não suportarem mais as implicações que essa convivência gera. Pode-se reconhecer a presença dessa sobrecarga nas falas a seguir:

"Que nem de noite eu não consigo dormir direito [...] eu fico nervosa" (E1) "Não dava mais para mim suportar, não podia mais com ele [...]”(E3)

"Nossa eu estava ficando louca também junto com ele." (E8)

"Passei o dia todo de cama com diarréia, por quê? Porque ela pegou um táxi e saiu, eu não sabia onde ela estava, comecei a ficar nervosa e ai, ataca a colite, gastrite na gente [...]” (E6)

Contribuem para o desgaste emocional dos cuidadores, além do que já apresentamos nessa temática, a percepção e as dimensões que estes têm sobre a repercussão da enfermidade em suas vidas.

Ao analisar a sobrecarga física e emocional, acreditamos que elas se refletem e não podem ser isoladas, visto que o ser humano é um ser biológico, emocional e social, o que acontece em qualquer dessas esferas reflete-se no todo. Esta, talvez seja a sobrecarga que mais compromete a qualidade de vida dos integrantes da família que convivem com o sofrimento mental, por interferir e implicar diretamente num processo de adoecimento desses e esmorecimento de suas estratégias de enfrentamento, as quais precisam ser trabalhadas para fortalecer os vínculos e a capacidade de prover o cuidado da família. 


\section{DISCUSSÃO}

Sobrecarga financeira: salientamos que muitas famílias vivem em situação econômica desfavorável, o que em parte as torna mais vulneráveis. Quando se trata da família que coexiste com o sofrimento mental, essa vulnerabilidade é intensificada e a dificuldade financeira agravada, pois a família vivencia um processo complexo, que exige uma nova estrutura nas relações de trabalho, nas inter-relações e no orçamento familiar. É preciso prever faltas ao trabalho para acompanhar e atender as demandas de cuidados do portador de transtorno mental, podendo comprometer a única fonte de renda da família.

As dificuldades se acentuam quando o responsável pelo cuidado é jovem e encontra-se em idade produtiva, e o tempo empregado para cuidar compromete aquele necessário para produzir renda ${ }^{(2)}$.

Os pais e demais familiares do portador de sofrimento psíquico custeiam os gastos relacionados à doença e suas conseqüências. O sustento da casa, a compra de medicamentos, as despesas com viagens, internações, médicos, precisam ser financiados com os recursos que outrora serviam para suprir as necessidades financeiras da família ${ }^{(11)}$.

É difícil de avaliar e quantificar a sobrecarga de quem convive com um portador de transtorno mental, mas é certo que as famílias sofrem privações econômicas por não contar com um integrante familiar inteiramente produtivo $^{(12)}$.

A sobrecarga financeira é expressa pela dificuldade do paciente em manter vínculo empregatício ou mesmo ingressar no mercado de trabalho após a manifestação da doença, pois este encontra muita dificuldade para produzir economicamente ${ }^{(13-14)}$.

A dificuldade do portador de sofrimento mental em conseguir inserir-se no mercado de trabalho está muito próxima da questão do preconceito. Quando consegue ter direito a um benefício financeiro, este pode minimizar os problemas gerados pela impossibilidade de trabalhar, e aumentar seu poder de contratualidade no grupo familiar. Salienta-se, então, a importância dos serviços substitutivos como os CAPS e das iniciativas de oficina de geração de renda, uma vez que estas resgatam a autoestima dos usuários, mostrando que são capazes de aprender e produzir.

Sobrecarga do cuidado: o cuidado familial pode ser reconhecido em vários atributos, entre eles a presença e a proteção. A presença compreende as ações, interações e interpretações por meio das quais, a família demonstra solidariedade aos seus membros, que é fundamental para o crescimento e desenvolvimento integral do ser humano. A proteção garante as medidas que dizem respeito à segurança física, emocional e social do grupo familiar, incluindo também a higiene pessoal e a salubridade ${ }^{(6)}$.
A família desenvolve estratégias e possui uma maneira peculiar de cuidar que, às vezes, não se constitui na melhor forma, mas é a maneira como ela se articulou para conseguir viver, uma vez que cuidar do portador de transtorno mental não é tarefa fácil, principalmente no quadro avançado de cronificação ${ }^{(4)}$.

Com a agudização da sintomatologia clínica, a família vivencia um processo de intenso sofrimento e, por vezes, de desespero, agravados pelas dificuldades que surgem no transcorrer dessa trajetória como conseqüência da doença, tais como: o sentimento de impotência e o adiamento de planos e expectativas referentes à vida pessoal o que abala e afeta, profundamente, o universo familiar. Desse modo, a pessoa responsável pelo cuidado passa a organizar sua vida em torno da doença e as suas necessidades pessoais são passadas para o segundo plano $^{(13)}$.

A convivência com o sofrimento psíquico é percebida pela família como difícil, pois muitas vezes não sabe como agir frente aos comportamentos adotados pelo familiar com transtorno mental ${ }^{(15)}$.

Cuidar de um familiar que sofre psiquicamente envolve uma relação que, por vezes, assemelha-se à relação estabelecida com crianças, sustentada por uma atitude de tolerância e paciência ${ }^{(16)}$.

O familiar responsável pelo cuidado demonstra preocupação e vigília quanto à administração correta dos psicofármacos, tomando para si a responsabilidade de atentar para os horários e a dosagem dos medicamentos, pois tem medo do uso inadequado que o portador de sofrimento psíquico possa fazer do mesmo, colocando sua vida em risco.

O cuidado prestado pela família visa preservar a vida de seus integrantes, possibilitando que estes alcancem o desenvolvimento pleno de suas potencialidades, de acordo com sua própria capacidade considerando as condições do meio onde vivem. A família é o núcleo onde se irradia o cuidado, o espaço onde o cuidar é aprendido ${ }^{(17)}$.

Sobrecarga física e emocional: muitos sintomas apresentados pelo portador de sofrimento psíquico quando não controlado, como conversar sozinho, agressividade, insônia, alteração do conteúdo do pensamento, perturbações da linguagem, da vontade e o comportamento imprevisível ou irresponsável, podem causar desgaste tanto físico como mental para o cuidador $^{(18)}$.

É preciso considerar que nem todas as pessoas conseguem assimilar e trabalhar as emoções envolvidas no cuidado a uma pessoa fragilizada pelos efeitos colaterais da medicação, excluída da sociedade e com o curso clínico indefinido da doença. As características da doença crônica (permanência, remissão, necessidade de diferentes intervenções) e o comportamento inadequado do paciente parecem favorecer a maior vulnerabilidade 
para as perdas, em geral, (da saúde, financeira, do equilíbrio físico, mental e emocional $)^{(19)}$.

Os familiares se percebem como mais nervosos, irritados, com falta de apetite e com distúrbios do sono $^{(18)}$, o que entendemos ser conseqüência da ansiedade por parte do cuidador, que está sempre alerta e com medo dos possíveis comportamentos que possam ser adotados pelo familiar enfermo.

A sobrecarga em forma de doença física e emocional é constatada pela alteração da dinâmica familiar, pelo aumento das demandas oriundas desta nova situação e pela falta de recursos de enfrentamento. Por este motivo, é comum o aparecimento de agravos físicos e emocionais como: problemas de coluna, hipertensão arterial, problemas cardíacos, estresse, tensão e nervosismo na família, após o diagnóstico de transtorno mental em um de seus integrantes ${ }^{(11)}$.

Um estudo analisando 40 famílias constatou que em 24 delas, outros integrantes apresentam sintomas psicológicos, como o desânimo em relação ao autocuidado, depressão, preocupações excessivas com os problemas decorrentes dos efeitos colaterais da medicação e a baixa auto-estima provocada pela estigmatização(20).

A convivência com o transtorno mental envolve questões complexas, uma vez que não é possível dissociarmos o "corpo doente", ou seja, o biológico das suas dimensões sociais que, neste caso, são representadas pelo contexto familiar. Tanto as limitações e o próprio sofrimento do portador de transtorno psíquico são vivenciados também pela família, confirmando a estreita relação entre o biológico e o $\operatorname{social}^{(21)}$.

\section{CONSIDERAÇÕES FINAIS}

Com a implantação dos serviços substitutivos em saúde mental, o portador de transtorno psíquico passa parte do dia no serviço e o restante do tempo convive com seus familiares, na tentativa de resgate da cidadania e dos vínculos que foram rompidos e negligenciados pela instituição asilar. Essa convivência, no entanto, como nem sempre se dá de forma harmoniosa, é em parte questionada, pois nem todas as famílias dispõem de estrutura e recursos de enfrentamento para coexistirem com o estigma social, com o descompasso temporal e os comportamentos inadequados do familiar que adoeceu.

Este estudo se propôs a conhecer a sobrecarga da família que convive com o sofrimento psíquico, constatando que essa realidade é permeada por sentimentos de desespero, ansiedade, preocupação e sofrimento, implicando em conflitos e tensões.

Entretanto, ao considerar que até mesmo os eventos previsíveis podem gerar certo nível de crise no núcleo familiar, a convivência com a realidade do transtorno mental também é mediada pela capacidade da família de ajustar-se à nova situação, dependendo das fortalezas que possui, dos laços de solidariedade que agrega e da possibilidade de acessar apoio de outras pessoas e instituições.

Não pretendemos apresentar a família como vítima da situação, sendo que entrevistamos apenas aqueles que participam de fato do cuidado ao portador de transtorno mental, não entrando na questão daquelas famílias que abandonaram seus familiares nas instituições psiquiátricas e que, hoje, nem sequer possuem uma identidade.

No atual contexto da assistência psiquiátrica, a família como espaço privilegiado para a prática do cuidado, precisa ser inserida de forma efetiva nas discussões do novo paradigma de assistência em saúde mental, vista como uma facilitadora no processo de reinserção social do portador de transtorno mental. Mais do que uma aliada na efetivação do modelo psicossocial emergente, ela deve ser encarada como foco de intervenção, para que seus anseios sejam acolhidos e sua sobrecarga minimizada.

As famílias precisam ser ouvidas, ter sua realidade/ sofrimento compreendida e acolhida, quando, muitas vezes, solicitam a internação do familiar doente não é por não amá-lo ou por fugirem da responsabilidade de, enquanto família, atender as necessidades de seus integrantes. Isso se dá porque não agüentam mais a convivência que, aos poucos, vai se tornando insustentável, difícil e desgastante, o que ressalta a importância de serem orientadas e apoiadas.

É importante inserir as famílias em grupos de familiares nos serviços comunitários de saúde mental, bem como, prestar esclarecimentos sobre o comportamento, a sintomatologia e o tratamento da enfermidade, sobre o uso dos psicofármacos e os efeitos colaterais dos mesmos, realizar visitas domiciliares para conhecer a realidade da família e fazer com que esta não se sinta sozinha. Ao contrário, deve sentir-se segura e capaz de agir de maneira adequada em relação aos sintomas apresentados pelo portador de sofrimento psíquico.

Os vínculos entre família e usuário de saúde mental necessitam ser alicerçados numa relação sincera e de respeito, onde a singularidade e individualidade de todos sejam preservadas, de forma que os primeiros não se sintam sobrecarregados, e os usuários possam efetivamente resgatar sua cidadania e autonomia em uma relação terapêutica.

\section{AGRADECIMENTO}

Agradecemos ao CNPq pelo apoio financeiro. 


\section{REFERÊNCIAS}

1. Galera SAF, Luis MAV. Principais conceitos da abordagem sistêmica em cuidados de enfermagem ao indivíduo e sua família. Rev Esc Enferm USP. 2002; 36(2):141-7.

2. Rosa L. A relação da família com o portador de transtorno mental. In: Rosa L. Transtorno mental e o cuidado na família. São Paulo: Cortez; 2003. p. 235-367.

3. Brasil. Ministério da Saúde. Secretaria de Atenção à Saúde. Legislação em saúde mental: 1990 - 2004. 5a ed. Brasília: Ministério da Saúde; 2004.

4. Waidman MAP. O cuidado às famílias de portadores de transtornos mentais no paradigma da desinstitucionalização [tese ]. Florianópolis: Programa de Pós-Graduação em Enfermagem da Universidade Federal de Santa Catarina; 2004.

5. Carvalho MCB. Família e políticas públicas. In: Kaloustian SM, organizador. Família brasileira, a base de tudo. São Paulo: Cortez; 1998. p. 93-108.

6. Elsen I. Cuidado familial: uma proposta inicial de sistematização conceitual. In: Elsen I, Marcon SS, Silva MRS. $O$ viver em família e sua interface com a saúde e a doença. $2 \mathrm{a}$ ed. Maringá: Eduem; 2002. p. 11-24.

7. Pereira MAO, Pereira Júnior A. Transtorno mental: dificuldades enfrentadas pela família. Rev Esc Enferm USP. 2003; 37(4):92-100.

8. Hirdes A, Kantorski LP. A família como um recurso central no processo de reabilitação psicossocial. Rev Enferm UERJ. 2005; 13(2):160-6.

9. Melman J. Família e doença mental: repensando a relação entre profissionais de saúde e familiares. São Paulo: Escrituras; 2002.

10. Wetzel C. Avaliação de serviço em saúde mental: a construção de um processo participativo [tese ]. Ribeirão Preto: Escola de Enfermagem de Ribeirão Preto da Universidade de São Paulo; 2005.

11. Koga M. Convivência com a pessoa esquizofrênica: sobrecarga familiar [dissertação ]. Ribeirão Preto: Escola de
Enfermagem de Ribeirão Preto da Universidade de São Paulo; 1997.

12. Moura DP. A enfermagem frente a socialização do ser humano esquizofrênico na família [monografia]. Pelotas: Faculdade de Enfermagem da Universidade Federal de Pelotas; 2005.

13. Melman J. Intervenções familiares no campo da reforma psiquiátrica. In: Fernandes MIA, Scarelli IR, Costa ES, organizadores. Fim de século e ainda manicômios? São Paulo: IPUSP; 1999. p.171-86.

14. Koga M, Furegato AR. Convivência com a pessoa esquizofrênica: sobrecarga familiar. Cienc Cuid Saude. 2002; 1(1):75-9.

15. Monteiro ARM, Barroso MGT. A família e o doente mental usuário do hospital-dia: estudo de um caso. Rev Latinoam Enferm. 2000; 8(6):20-6.

16. Catena RM, Galera SAF. Doente mental e família: estes desconhecidos. Acta Paul Enferm. 2002; 15(1): 53-8.

17. Delgado JA . Família vivenciando situações de saúde-doença: um conhecimento em construção. In: Elsen I, Marcon SS, Silva MRS. O viver em família e sua interface com a saúde e a doença. 2a ed. Maringá; 2004. p. 285-394.

18. Furegato ARF, Silva EC. O fardo e as estratégias da família na convivência com o portador de doença mental. Texto \& Contexto Enferm. 2002; 11(3):51-6.

19. Oliveira RMP, Loyola CM. Família do paciente psiquiátrico: o retrato de uma ilustre desconhecida. Acta Sci, Health Sci. 2004; 26(1):213-22.

20. Marcon SS, Waidman MAP, Carreira L, Decesário MN. Compartilhando a situação de doença: o cotidiano de famílias de pacientes crônicos. In: Elsen I, Marcon SS, Silva MRS. O viver em família e sua interface com a saúde e a doença. 2a ed. Maringá; 2004. p. 265-281.

21. Reinaldo A, Wetzel C, Kantorski LP. A inserção da família na assistência em saúde mental. Saude Debate. 2005; 29(69):5-16. 